\title{
TREATMENT OF CARBON MONOXIDE POISONING BY MECHANICAL VENTILATION: CASE REPORT
}

\author{
Gary L. Townsend, M.D., and John B. Stetson, M.D. $†$
}

Suicroe is among the ten leading causes of death in industrialized countries. During 1965 there were 22,000 reported suicides in the United States (statistics compiled by the Center for Studies of Suicide Prevention). There is no way of estimating the incidence of unreported suicides, or of the number of survivors after attempted suicide.

One of the more frequent modes of suicide is carbon monoxide inhalation. As an accidental cause of death, carbon monoxide poisoning ranks second only to alcohol. ${ }^{1}$ This, combined with the increasing incidence of non-accidental carbon monoxide poisoning, has made the acute management of these cases a pertinent problem in modern medicine. As an example of the extent of the "disease," in the period 1950 to 1955 , carbon monoxide poisoning represented 2.1 per cent of cases investigated by the Los Angeles county coroner's office ( 875 of 41,615$).^{2}$ Mann, in 1958, found 1,156 cases of carbon monoxide poisoning out of a total of 18,513 suicides. $^{3}$ In the state of Indiana, in 1965 , there were 80 suicides by carbon monoxide inhalation and 47 accidental poisonings. ${ }^{4}$

Carbon monoxide has been termed the perfect asphyxiant. Haemoglobin combines with carbon monoxide $200-300$ times as readily as it does with oxygen and dissociates from it 250 times as slowly. ${ }^{5}$ The poisonous effects of carbon monoxide are derived from its double action in the production of asphyxia. First, any excess in inspired air reduces the percentage of oxygen inhaled. Second, it forms a stable compound with haemoglobin, and the carboxy-haemoglobin interferes with dissociation of any oxyhaemoglobin which remains in the erythrocytes. (Consequently, the tissue damage done by carbon monoxide poisoning results from histotoxic anoxia secondary to anoxemia.) Removal of carbon nonoxide is also hindered by the insufficient supply of oxyhaemoglobin to act as a catalyst in the liberation of carbon monoxide.

The prominent neurological sequelae of carbon monoxide poisoning result from damage to the basal ganglia; most commonly the globus pallidus, and sometimes the head of the caudate nucleus and putamen. There is a softening and necrosis of the basal ganglia as well as damage to the reticular zone of the substantia nigra and the deeper layers of Purkinje cells of the cerebellum.

If the patient survives into the chronic stage in which residuals of carbon monoxide are seen, three patterns are evident. The patient may survive for several months and then succumb after a progressive downhill course (progres-

\footnotetext{
'From the Vital Function Laboratory Indiana University Medical Center, Indianapolis, Indiana.

fDr. Stetson is Associate Professor and Associate Director, Division of Anesthesiology, Ohio State University Hospitals, 410 W. 10th Ave., Columbus, Ohio 43210. Reprint requests should be sent to him.
} 
sive demyelination). He may live for months or years with a characteristic striatal syndrome (central necrosis of the globus pallidus). Or he may survive with only occasional epileptiform seizures or an organic psychosis (widespread nodular cortical atrophy). ${ }^{6}$

The medical symptoms of carbon monoxide poisoning are protean. The most prominent are neurologic and include blurring of vision, pain in the eye, vertigo, tinnitus, deafness, speech abnormalities, weaknesses in the legs, somnolence, yawning, nausea, ataxia, and clonic-tonic spasms. The incidence of neurological sequelae such as epilepsy, Parkinsonism, multiple sclerosis, psychomotor seizures, and encephalitis is higher in those with deep and prolonged coma as well as those exposed to chronic carbon monoxide poisoning. ${ }^{\top}$

Mental and cardiac changes are also a prominent part of the syndrome. Mental sequelae consist of confusion psychosis with disorientation, lack of judgment, amnesia, and, less commonly, motor overactivity and aphasia. ${ }^{8}$ Cardiac manifestations include palpitations, tachycardia, arrhythmias, and in severe cases bradycardia or complete heart block. ${ }^{9}$

Although the pathology and symptomatology of carbon monoxide poisoning are well known, the treatment of this medical emergency has remained ill defined. Most recent attention has been focussed on the use of hyperbaric oxygen therapy. ${ }^{10}$ During a one-year period, Smith and his colleagues treated all severely gassed patients admitted to the Western Infirmary, Glasgow, with oxygen at two atmospheres pressure. The patients attained consciousness in 30 to 60 minutes. Over 30 patients considered moribund on admission as a result of coal gas fumes were treated successfully without residual EKG changes or signs of mental deterioration. ${ }^{11}$

Smith, Sharp, and Ledingham have now built up a case study of 70 patientsonly three of whom had not conformed to the usual pattern of recovery. Two of the three were older patients who had been exposed to coal gas for more than eight hours. The third had received conventional therapy for three hours before transfer. ${ }^{12}$

In another study, Pace, Strajman, and Walker ${ }^{13}$ treated carbon monoxide intoxication in ten volunteers. They received 100 per cent oxygen at 2.5 atmospheres absolute with moderate to marked improvement in each case.

Sluijter (Dec. 1960-Aug. 1962) treated all patients with carbon monoxide poisoning brought to the Wihelmina Gasthuis in Amsterdam by administration of 100 per cent oxygen at a pressure of three atmospheres absolute. Duration of treatment at full pressure was 20 minutes minimum and 60 minutes maximum. In all, 40 patients were treated. The clinical results in the treatment of patients who were conscious or lightly comatose upon admission were excellent, but in patients where coma was deep enough to cause hypotension, only four showed evidence of any improvement in the level of consciousness. ${ }^{14}$

Although the results of treatment with hyperbaric oxygen are at times impressive, this method of treatment has several intrinsic drawbacks. The chambers themselves are extremely expensive and limit treatment to one or two centres. The travel time to these centres dissipates much of the gain in rapid carbon monoxide removal. 
To offset these difficulties, mobile hyperbaric tanks were manufactured in Great Britain for use in certain industrial areas in England and Scotland. The authors have no experience with these units. The geographic and economic conditions of North America are so different from those of Great Britain that it is doubted that such a unit would be of service on this side of the Atlantic. The "Flying Squad" concept of medicine in Great Britain is centred on a wellequipped van. In most of North America, a multi-engined aircraft would be necessary for rapid transit over vast areas, and the squad would be literally Alying. A huge helicopter (or team of helicopters) might perform this service in the growing megalopolis areas.

Central heating is standard in North America. This reduces the incidence of accidental poisoning caused by poorly ventilated flats and terrace homes. As the economic level of those poisoned would tend to be higher in this continent, the victim would probably be brought to his local hospital rather than a regional infirmary or centre. (It is difficult to correlate British and North American medical practice; most North American community hospitals fall between the British "cottage hospital" and the regional centre in size, but are generally well equipped for all types of medical and surgical practice.) Most North American hospitals have a mechanical respirator. As knowledge about ventilatory care increases in the medical community, more and more of the ventilators purchased are of the "volume" type rather than the "pressure" type.

The following case report illustrates the successful treatment of a case of carbon monoxide intoxication with an increasing-force volume ventilator, an anti-inflammatory drug, and general "intensive care."

\section{CASE History}

The patient was a fifteen-year-old female. She was found on the front seat of her family automobile in a comatose condition at 6:00 A.M. on September 26, 1966. The garage door was closed, the car windows were open. The ignition was turned on, but the motor was not running and the gas gauge did not show any substantial decrease from the previous night's reading. She was immediately taken to the local hospital where oxygen therapy was given by mask. She was then transferred to the James Whitcomb Riley Children's Hospital at the Indiana University Medical Center.

She arrived in the admitting room at 11:00 A.M. On physical examination, she appeared as a well-developed, well-nourished female in comatose condition with mild intermittent decerebrate rigidity and extensor spasm. Blood pressure was $105 / 75$, pulse was 190 , respirations were irregular, and the patient's temperature was $102.5^{\circ}$ F. rectal. Examination of her head showed a small abrasion of the left temple and small abrasion under the right temple with a larger haematoma over the midline of the scalp posteriorly. It was assumed these injuries were self-inflicted during convulsive movements as there was no access for attack. (Bruising is facilitated by carbon monoxide poisoning.) The pupils were equal and reacted to light and accommodation. The eyes were conjugately deviated 
to the right with searching movements. Cupping of the discs was not prominent. The lips were not "cherry-red" in color. There was a large amount of foamy secretion in the mouth with moderate airway obstruction. There were ronchi and coarse rales throughout both lung fields. The heart rate was regular and there was no evidence of any murmurs or rubs. The examination of the abdomen and the genitourinary system was within normal limits. There was no evidence of any vaginal discharge or instrumentation. The patient responded to painful stimuli by withdrawing all her extremities but there was a slightly decreased movement on the right. Her hands were held in a flexed position with arms extended. There was unsustained ankle clonus and absent Babinski response bilaterally. Deep tendon reflexes were hypoactive in all extremities.

Later review of the patient's past history was not remarkable except for an incident of swallowing a handful of aspirins in an attempted suicide eight weeks prior to this hospital admission.

Pertinent laboratory data upon admission included a carbon monoxide level of 12 per cent (a low value which was probably a result of four hours of oxygen therapy prior to admission). Barbiturates were not present. Acetylsalicylic acid level was $0.9 \mathrm{mg}$. Serum calcium was $9.0 \mathrm{mEq}$./L., blood sugar 112, haemoglobin 13.5, haematocrit 39 per cent, white blood cell count 19,900, chloride 102 , bicarbonate 18.2, sodium 138, and potassium 3.0. Lumbar puncture on admission demonstrated clear fluid with an opening pressure of $80 \mathrm{~mm}$. water (22-gauge needle). Catheterized urine (200 c.c.) was pheno-stik negative for acetylsalicylic acid. Urine analysis showed specific gravity $1.019, \mathrm{pH} 5.0$, protein $1+$, acetone negative, glucose negative, $30-40$ white blood cells, and 6-8 red blood cells per high-powered field.

Blood gas studies upon admission revealed a $\mathrm{Po}_{2}$ of 78 and $80, \mathrm{PCO}_{2}$ of 23 and 24 , and $\mathrm{pH}$ of 7.43 and 7.44. All blood gas studies are performed simultaneously on two separate instruments (both Instrumentation Laboratories model $113 \mathrm{S1}$ ). The meters were always standardized with Instrumentation Laboratory buffer and gas mixtures immediately before use. United States Weather Bureau barometric readings were used.

The patient was given 22 milliequivalents of sodium bicarbonate intravenously and placed on a Temptrol blanket. She was then intubated with a cuffed (not inflated) $8 \mathrm{~mm}$. portex tube and placed on an Engström respirator. As the patient was convulsing at the time of intubation there was some difficulty in exposure of the glottis.

Local consultants reported that all children previously seen with decerebrate rigidity following carbon monoxide poisoning had expired. For this reason there was no opposition when it was suggested she be placed on prolonged ventilator therapy in the intensive care unit. The course of therapy during the patient's acute illness is summarized in Table I.

The metabolic response by tissue to any type of trauma is the retention of water. The cerebral oedema caused by the trauma of carbon monoxide poisoning effects an increase in the oxygen pressure gradient between capillary cells and produces a secondary hypoxia. The ultimate success of therapy depends on the 


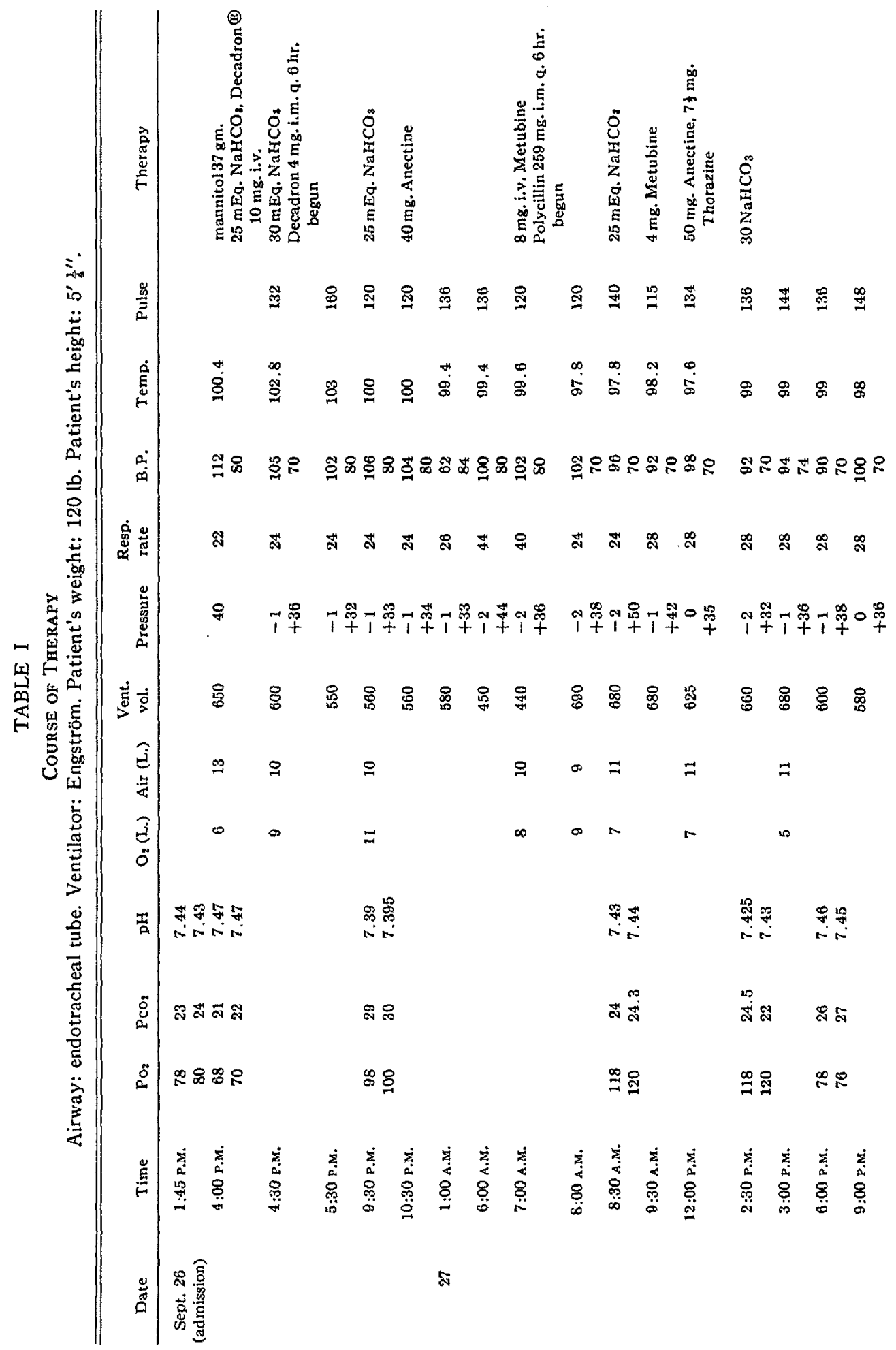




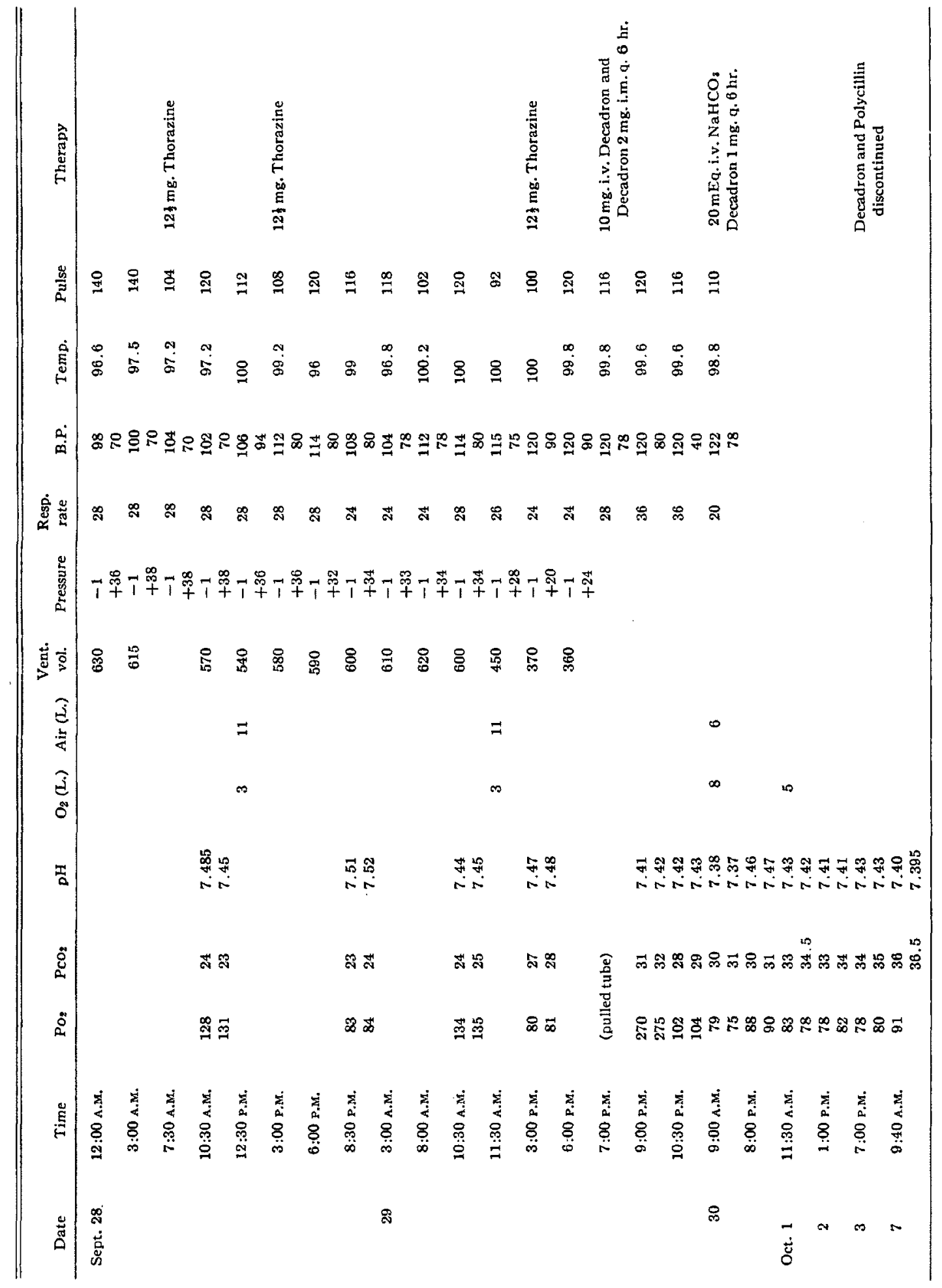


degree and duration of the associated anoxia. Cerebral oedema was felt to be present even though cerebral spinal fluid pressure was not elevated. Consequently the initial aim of the respirator therapy was the reduction of cerebral oedema. This was accompanied by a rapid ventilatory rate ( 24 per minute) and relatively large expiratory volume $(600-690 \mathrm{ml}$.). The results were monitored by frequent arterial blood gas determinations which values we attempted to stabilize at a $\mathrm{PO}_{2}$ of $100-120$ and $\mathrm{PCO}_{2}$ of 24 . It was felt the reduced $\mathrm{PCO}_{2}$ would decrease cerebral blood flow and lower intercerebral pressure (Fig. 1). Sodium bicarbonate was given intravenously to combat the metabolic acidosis which was secondary to increased lactic acid from anoxia. ${ }^{15}$

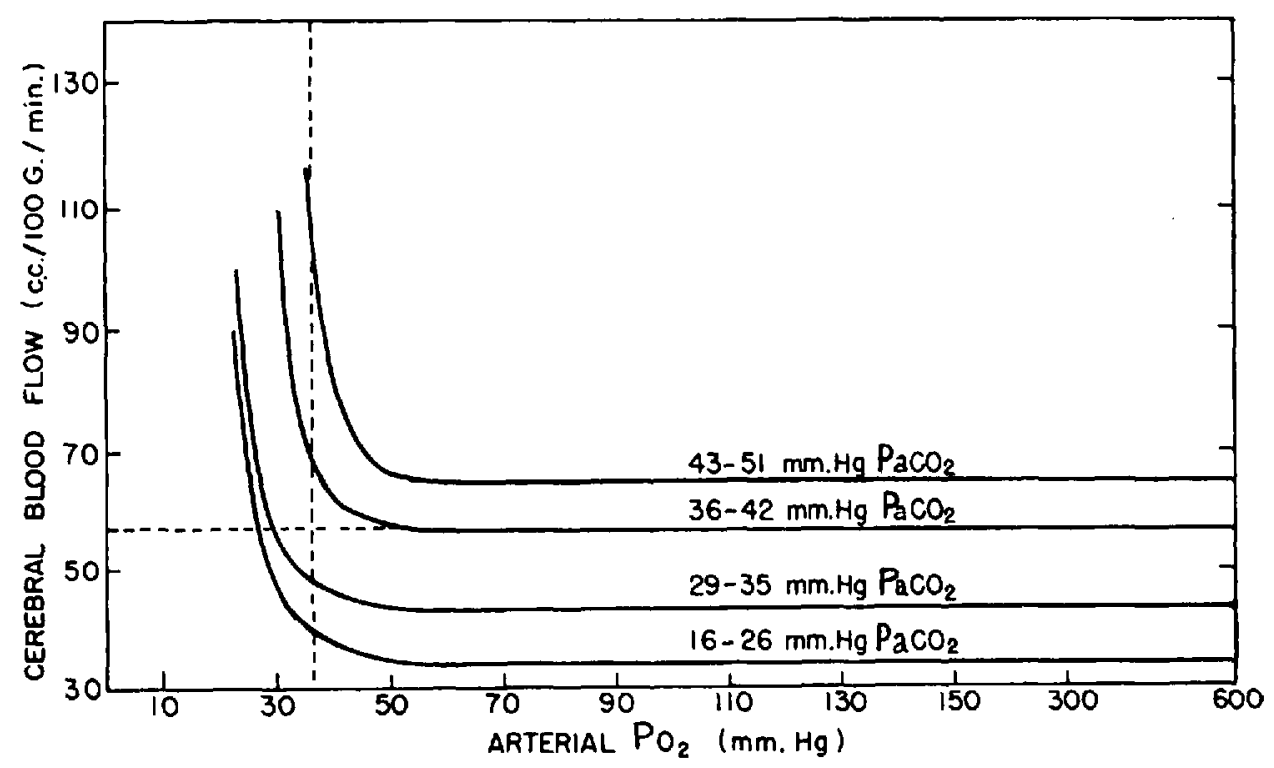

Frgure 1. Relationships among $\mathrm{Pa}_{2}, \mathrm{~Pa}_{\mathrm{CO}_{2}}$, and rate of brain blood flow (based upon 56 measurements in seven normal men). Above about $50 \mathrm{~mm}$. $\mathrm{Hg}$, arterial oxygen tension exerts no important effect upon blood flow. The vasodilator action of low $\mathrm{Pa}_{2}$ becomes increasingly prominent as $\mathrm{Pa}_{2}$ falls below $50 \mathrm{~mm}$. $\mathrm{Hg}$. By varying $\mathrm{Pa}_{\mathrm{CO}_{2}}$, wide fluctuations in brain blood flow can be produced both in the absence and in the presence of anoxemia; actually hypocapnia is capable of reversing, and hypercapnia of exaggerating, the cerebral vasodilatation normally associated with anoxemia. The figure shows that a particular rate of cerebral blood flow can be obtained over a wide range of variation of $\mathrm{Pa}_{2}$ and $\mathrm{Pa}_{\mathrm{CO}_{2}}$. (From an article by C. J. Lambertsen in Cerebral Ischemia and Infarction, ed. Ludwig and Elson. American Practitioner. 12: 149 (1961).)

The patient was also treated with dexamethasone (Decadron $\left.{ }^{(}\right)$to further reduce cerebral oedema. Decadron was chosen because of its marked anti-inflammatory potency and low salt-retaining activity. Its efficiency in combating cerebral oedema has been established.

Galich and French noted marked reduction in cerebral oedema in 18 of 21 patients with brain tumours, and in 10 of 13 patients with evidence of postoperative brain oedema treated with dexamethasone. They administered $10 \mathrm{mg}$. of Decadron intravenously and $4 \mathrm{mg}$. intramuscularly every six hours for two to 
four days and then 1 to $3 \mathrm{mg}$. orally thrice daily for another five to seven days. The decrease in cerebral oedema was manifested by a reduction in papilloedema, vomiting, headache, and a decrease in intracranial mass evident on direct observation. ${ }^{16}$

This supported the work by Russek ${ }^{17}$ and Roberts ${ }^{18}$ who observed a relief of cerebral oedema manifested by an improvement in the mental and neurological status of patients with cerebral infarction treated with glucocorticoids.

Following admission, $10 \mathrm{mg}$. Decadron was administered intravenously and $4 \mathrm{mg}$. intramuscularly every six hours. Decadron was also utilized for its salutory effects in combating aspiration pneumonitis. ${ }^{10-22}$ The patient's admission chest film revealed an infiltrative process in the right lung with patchy infiltrates on the left. It was felt that the patient exhibited Mendelson's syndrome (aspiration of liquid material producing cyanosis, tachycardia, and dyspnoea, but with no mediastinal shift or massive atelectasis). The patient was not in shock, but if this condition was incipient, the dexamethasone would have had a salubrious effect. ${ }^{23-25}$

Thirty-seven grammes of mannitol (25\% solution) were also given intravenously upon admission to further reduce cerebral oedema. Mannitol was chosen over urea and hypertonic glucose because it is a large molecule and avoids the rebound rise in cerebrospinal fluid pressure which is associated with smaller molecules.

The combination of mannitol, Decadron, and hyperventilation was successful in reducing cerebral oedema, and by the morning of September 29, 1966 (fourth hospital day), the patient was completely alert and responsive to all questions. At this point, she had been on the Engström respirator for 66 hours. During this period, the patient had been maintained in rhythm with the respirator with only the occasional use of intravenous succinylcholine and dimethyl curare. A total of $90 \mathrm{mg}$. of the former and $12 \mathrm{mg}$. of the latter were used. When patients are adequately ventilated they will generally remain passive during mechanical ventilation. The patient's cerebral injury (or metabolic acidosis) may have triggered the attempts to breathe that caused the need to use relaxants. Chlorpromazine was given intravenously to combat restlessness.

During ventilator therapy the patient exhibited a mild metabolic acidosis. It is not known if this was due to the carbon monoxide poisoning or the hyperventilation ${ }^{26}$ employed in treating the patient. The importance of hyperventilation in the production of metabolic acidosis is at present a subject of debate. ${ }^{27,28}$ The metabolic acidosis was treated with intravenous sodium bicarbonate. The treatment was not vigorous. The base deficit per litre of blood was computed from a Singer-Hastings ${ }^{29}$ nomogram. The deficit was multiplied by $.075 \times$ patient's body weight in kilograms. The figure of .075 was taken as a reduced female blood volume. There was no attempt to produce a marked alkalosis. By keeping the $\mathrm{pH}$ near normal, the Bohr effect was avoided, and it is assumed the oxygen dissociation curve maintained its normal configuration. Perhaps this was an undue worry in that Kety and Schmidt ${ }^{30}$ have shown normal cerebral oxygen consumption during hyperventilation.

In general, we use large-tidal-volume, slow-rate ventilation. Most patients are 
more pleased and relaxed with this style of ventilation than with rapid, smalltidal-volume breathing. During the night of the 27th (second hospital day), a rapid rate with small tidal volumes was tried by a relief house officer. The patient continued restless and was curarized. In the morning the patient was returned to her former respiratory pattern with good clinical results.

If the tidal volumes on Table I appear large for a patient of this size, it must be remembered that the Engström ventilator has a large compressible volume (Fig. 2). S. Alvar Swensson has amply reviewed this subject. ${ }^{31}$ As all ventilators have compressible volume, use of the Radford nomogram for ventilatory control will lead to under-ventilation. Expiratory ventilometers, no matter whether electronic or mechanical, operate at room ambient pressure. This pressure is zero

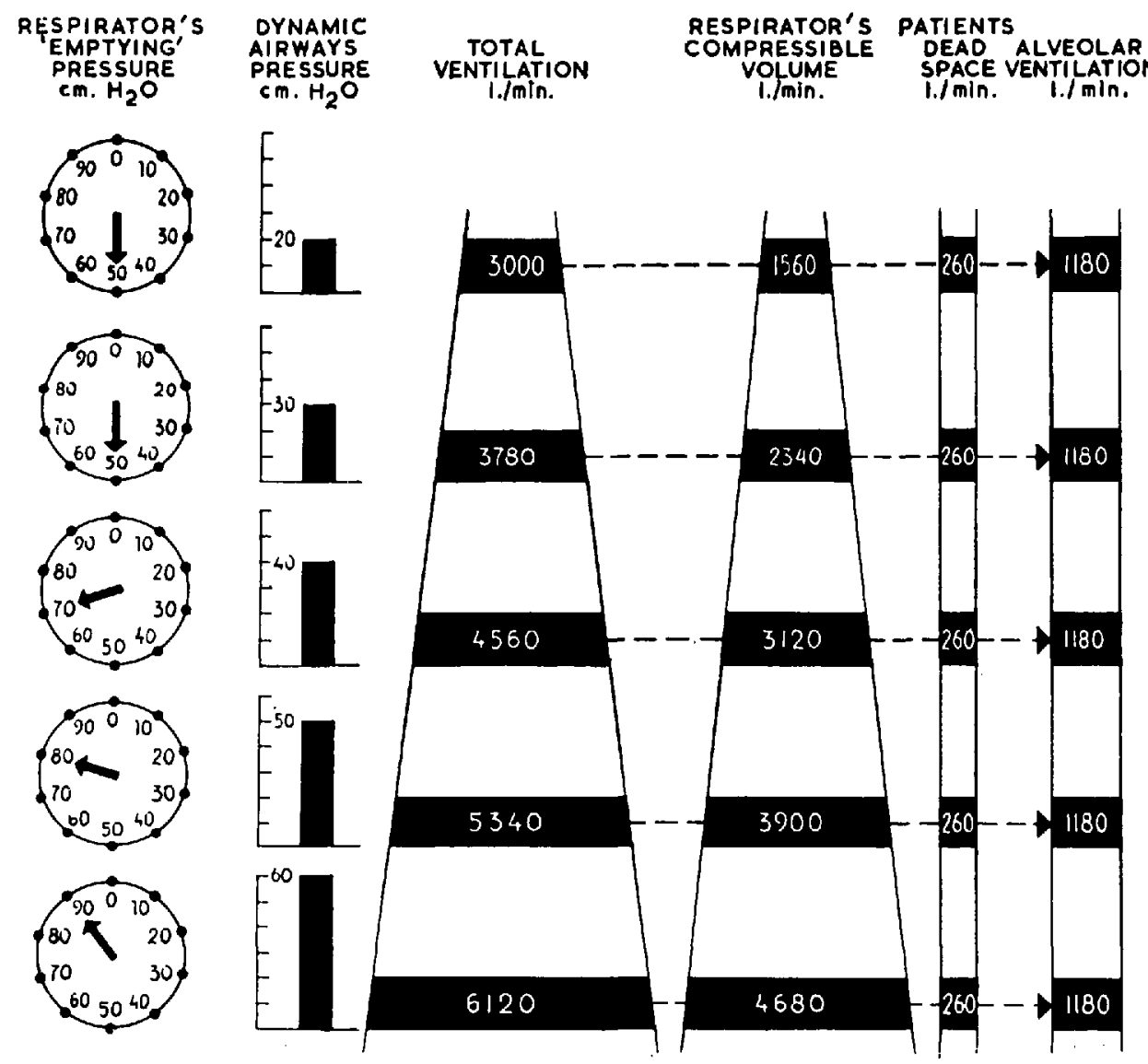

Frgune 2. Any ventilator has compressible volume. This is the volume between the patient's lungs and the source of "air" in the ventilator. In the Engström, this includes the air in the rubber bag, air in all the tubing on the top of the machine, to and from the patient, and air over the water in the humidifier. As expiratory volume is read out at room ambient pressure, the air compressed in the machine expands before being recorded by the ventilometer. As pressure goes up, total minute ventilation must increase to maintain a constant alveolar ventilation. The "respirator's emptying pressure" refers to the pressure around the rubber bag on the Engström. It is read on the dial on the right side of the control panel. In the example, it is kept 20 to $30 \mathrm{~cm} . \mathrm{H}_{2} \mathrm{O}$ above the airway pressure. (Illustration after S. A. Swensson. Arch. Dis. Childhood. 37: 156 (1962).) 
on the ventilator's pressure manometer. During inspiration, a positive pressure will be shown on the machine's pressure manometer. This is not the patient's airway pressure, but the pressure at the point where sampled. On the Engström ventilator, the pressure shown on the water manometer will be higher than the pressure recorded on the fine pressure manometer. The water pressure manometer reflects the resistance to air flow of the valve box and the humidifier screen. Both manometers reflect the resistance of the delivery tubes, the catheter connector and "Y," and the endotracheal or nasotracheal tube. If the Engström ventilator is set up for ventilating an infant through a $3 \mathrm{~mm}$. nasotracheal catheter, the water manometer may record $18 \mathrm{~cm}$. of water pressure, and the fine manometer $15 \mathrm{~cm}$. of pressure if the machine is operated before the tracheal catheter is placed.

Negative pressure is applied with the ventilator's venturi apparatus. We tend to use a value of 1 to $2 \mathrm{~cm}$. of water negative pressure at the fine pressure manometer. The purpose of the negative pressure is to overcome the machine's expiratory resistance. When the "three-way stop cock" is switched to "spirometer" an immediate rise in airway pressure is recorded at the fine pressure manometer. Much of the resistance to expiration is at the valve box. The use of the venturi removes this resistance. By the use of the venturi, oesophageal pressures are brought to zero during expiration. We do not try to obtain a negative transmural pressure as we feel this may lead to air trapping and/or miliary atelectasis. Use of a ventilator, such as the Emerson Pav, with negligible expiratory resistance obviates the necessity of a venturi attachment.

The Engström ventilator does not have a sigh attachment. To compensate for the lack of air automatic sigh, every fifteen minutes the air dosing valve was opened an additional seven litres on the dial setting for three to five breaths. The patient was also sighed before and after tracheobronchial toilet. Care of the airway was by sterile technique using sterile disposable plastic gloves and suction catheters.

Sterile intravenous saline solutions were used for lavage ( 1 to $3 \mathrm{ml}$.) prior to suctioning. The external diameter of the suction catheter was never over half the internal diameter of the endotracheal catheter. The suction catheters were on a "Y," with one arm open to air until the catheter was fully advanced into the lungs. A stethescope was used to monitor suctioning to assure cleansing of both lungs.

The patient was turned each hour with emphasis on positioning to augment drainage from lobes most severely affected by her aspiration pneumonitis. With turning, the patient also received chest succussion to loosen secretions.

As the patient did not appear to be suffering from ileus, a gastric feeding tube was passed after she was settled on the ventilator. Gavage feedings of $30 \mathrm{ml}$. per hour of a low viscosity fluid were started. The feedings yielded 1,800 calories per litre. Maintaining caloric intake reduces body protein loss and increases body resistance to infection.

Urine was collected in a closed sterile system. As renal function was unimpaired, no difficulties were encountered in maintaining water and electrolyte balance.

At 6:00 P.M. on September 29, the patient removed her endotracheal tube. There was no respiratory difficulty at that time, and the decision was made not to 
reintubate her. Ten milligrams of Decadron was given intravenously to combat laryngeal oedema, and the patient was treated with mist from a DeVilbiss nebulizer. Oxygen at $15 \mathrm{~L} . / \mathrm{min}$. was added to the air blower output (about $30 \mathrm{~L}$. of air). The patient did not object to the use of a face mask for delivery of the mist. A mixture of one-quarter sterile saline and three-quarters sterile distilled water was used as a fluid for nebulization. The nebulizer was set at output top \#3. At this setting, the machine should deliver slightly over $4 \mathrm{ml}$. of nebulized fluid per minute.

The patient's subsequent hospital course was essentially unremarkable. She continued to have right-sided weakness, most marked in the upper extremity, and spasticity and increased deep tendon reflexes in the lower extremities (again, most marked on the right side). An electroencephalogram on October 26 (one month after injury) revealed abnormalities in the left pariental region.

Despite her marked neurological improvement, the patient's hospital stay was prolonged for continued medical observation. A recent article in the British Medical Journal ${ }^{32}$ had pointed out the danger of an early return to normal physical activity after an episode of carbon monoxide poisoning. The authors reviewed a case of mental relapse 21 days after recovery of normal status and correlated this relapse with a high incidence of sudden death. We considered this report an indication for prolonged hospitalization. However, the patient was removed from the medical centre by her parents against medical advice on November 3, 1966.

A follow-up clinic visit on December 6, 1966, revealed a "normal" mental status. There was no abnormal weakness and Babinski's signs were absent bilaterally. The patient did retain a moderate hyper-reflexia and spasticity in the right lower extremity. A repeat electroencephalogram was within normal limits.

\section{Conclusion}

The treatment of carbon monoxide poisoning by a mechanical respirator has been a neglected subject in the world literature. Instead, interest has centred on hyperbaric oxygenation. We believe that mechanical hyperventilation offers an effective and economic alternative treatment of acute carbon monoxide poisoning.

Numerous authors have stated that endotracheal tubes cause laryngeal oedema and actual necrosis if retained longer than 24 hours. ${ }^{33}$ It has been our experience in the management of postoperative cardiovascular patients that tracheal tubes may be employed from seven to fourteen days without ill effects.

As experience has been gained, we have used smaller and smaller tracheal tubes. Air leakage around the tube is not a problem with a volume ventilator. We have used sterile thermolabile portex tubes. Tubes are not reused. Nasal tubes are changed every several days from nostril to nostril. Tubes below $4.0 \mathrm{~mm}$. internal diameter are changed every two days as a precaution against mucus plugging. Following prolonged intubation we have seen an increasing incidence of a whitecoloured tissue reaction in the glottic ring. We have attributed this to iatrogenic infection. Recent articles by Guess ${ }^{34,35}$ have made us reconsider the cause of this 
tissue reaction, which may be the product of a change in the formulation of the P.V.C. used in our tracheal tubes, resulting in a greater elusion of toxic materials. Attempts will be made to tissue-test our materials.

Although we are concerned about the dangers of prolonged intubation, we have had a higher incidence of serious management complications with tracheostomies. For this reason we prefer oral or nasal intubation for disease that will resolve. If our patient had not regained consciousness in a week or two or had showed evidence of extensive brain damage, we would have changed to tracheostomy ventilation as it reduces nursing care of the oro- and nasopharynx.

\section{SUMMARY}

Severe carbon monoxide poisoning is a not uncommon disease in North America. The authors were privileged to treat a fifteen-year-old female who had attempted suicide with carbon monoxide. When first seen, she exhibited decerebrate rigidity and evidence of aspiration pneumonitis. She was treated with prolonged tracheal intubation and moderate hyperventilation. She also received dexamethasone as an anti-oedema and anti-inflammatory agent. The patient "awoke" after sixty hours of ventilator therapy. She subsequently recovered from most of her neurologic injuries. She is said to be the first survivor (in this area) of carbon monoxide poisoning with decerebrate rigidity.

\section{RÉSUMÉ}

En Amérique du nord, l'empoisonnement grave au monoxyde de carbone n'est pas une maladie rare. Les auteurs ont eu la bonne fortune de traiter une jeune fille de 15 ans qui avait tenté de se suicider avec du monoxyde de carbone. A son premier examen, elle présentait des signes de rigidité décérébrée et de pneumonie d'aspiration. Le traitement a consisté en une intubation endotrachéale prolongée et en une hyperventilation modérée. Elle a reçu également de la déxaméthasone comme agent anti-inflammatoire et anti-oedemateux. La malade s'est réveillée après six heures de thérapie ventilatoire. Subséquemment, toutes ses sequelles neurologiques sont disparues. Dans la région, on s'accorde à dire qu'elle est la première survivante à un empoisonnement au monoxyde de carbone avec rigidité décérébrée.

\section{REFERENCES}

1. Kaye, S. Carbon Monoxide Poisoning. Virginia M. Month. 84: 627 (1957).

2. Courville, CyrIl B. Forensic Neuropathology: Chapter I, The Asphyxiant Gases. J. Forensic Sc. 9: 19 (1964).

3. Mann, Joseph. EEK Changes and Psychiatric Findings in Suicidal Carbon Monoxide Poisoning. Dis. Nerv. System 26: 508 (1958).

4. Statistics compiled by the Director of Public Health Statistics for the State of Indiana.

5. Carbon Monoxide: A Stealthy Killer. Anesth. \& Analg. 45: 664 (1965). Reprinted from Pfizer Spectrum.

6. Courville. Op. cit. 29.

7. Gilbert, G. J. \& Glaser, G. H. Neurologic Manifestations of Chronic Carbon Monoxide Poisoning. New England J. Med. 261: 1217 (1959). 
8. Shillito, F. H.; Drinker, C. K.; \& Shaughnessy, T. J. The Problem of Nervous and Mental Sequelae in Carbon Monoxide Poisoning. J.A.M.A. 106: 669 (1936).

9. Schafer, Nathianiel; Smlay, Malcolm G.; \& MacMillan, Francis P. Primary Myocardial Disease in Man Resulting from Acute Carbon Monoxide Poisoning. Am. J. Med. 38: 316 (1965).

10. Barach, Alvan L. Hyperbaric Oxygen and Current Medical Uses of Oxygen. New York J. Med. 63: 2775 (1963).

11. SMITr, G. et al. Treatment of Coal Gas Poisoning with Oxygen at Two Atmospheres' Pressure. Lancet, $i: 816$ (1962).

12. Smith, G.; Sharp, G. L.; \& Ledingham, I, M. Treatment of Coal Gas Poisoning in Humans by Oxygen under Pressure. Scottish M. J. 6: 339 (1961).

13. Pace, N.; Strajman, E.; \& Walker, E. L. Acceleration of Carbon Monoxide Elimination in Man by High Pressure Oxygen. Science. 111: 652 (1950).

14. Slujter, M. E. The Treatment of Carbon Monoxide Poisoning by Administration of Oxygen at High Atmosphere Pressure. Proc. Roy. Soc. Med. 56: 1002 (1963).

15. Leathaft, G. L. Hyperventilation in Carbon Monoxide Poisoning. Brit. M. J. 5303: 511 (1962).

16. Galich, T. H. \& French, Lyle A. Use of Dexamethasone in the Treatment of Cerebral Edema Resulting from Brain Tumors and Brain Surgery. Am. Pract. Digest Treat. 12: 169 (1961).

17. Russex, H. I.; Johnson, B. L.; \& Russex, A. S. Cortisone in the Immediate Therapy of Apoplectic Stroke. J. Am. Geriat. Soc. 2: 216 (1954).

18. Roberts, A. T. Supportive Adrenocortical Therapy in Acute and Subacute Cerebrovascular Accidents with Particular Reference to Brain Stem Involvement. J. Am. Geriat. Soc. $6 ; 686$ (1958).

19. Bannister, W. K.; Satillaro, A. J.; \& Otis, R. D. Therapeutic Aspects of Aspiration Pneumonitis. Anesthesiology. 22: 440 (1961).

20. Bannister, W. K. \& Satillaro, A. J. Vomiting and Aspiration during Anesthesia. Anesthesiology. 23: 251 (1962).

21. Dines, D. E.; Baken, W. G.; \& Scantland, W. A. Aspiration Pneumonitis-Mendelson's Syndrome. J.A.M.A. 176: 229 (1961).

22. Heironemus, T. W., II. Regurgitation and Aspiration during Anesthesia (Mendelson's Syndrome). Virginia M. Month. 90: 162 (1963).

23. Howland, W. S.; Schweizer, Olga; \& Dotтo, Alma. Treatment of Adrenal Cortical Insufficiency during Surgical Procedures. J.A.M.A. 160: 1271 (1956).

24. JACKson, B. B. The Use of Adrenal Steroids in the Treatment of Sudden Collapse Associated with Surgery: Five Cases. South. M.J. 52: 1380 (1956).

25. Schneewind, J. H. \& Cole, W. H. Steroid Therapy in Surgical Patients. J.A.M.A. 170: 1411 (1959).

26. Papadopoulos, C. N. \& Keats, A. S. The Metabolic Acidosis of Hyperventilation Produced by Controlled Respiration. Anesthesiology. 20: 156 (1959).

27. Dobrin, Allen. Metabolic Acidosis and Hyperventilation. Anesthesiology. 20: 721 (1959).

28. Dobkin, Allen. Metabolic Acidosis. Anesthesiology. 21: 87 (1960).

29. Singer, R. B. \& Hastincs, A. B. Improved Clinical Method for Estimation of Disturbances of Acid-Base Balance of Human Blood. Medicine. 27: 223 (1948).

30. Ketr, S. S. \& SchMm, C. F. The Effects of Active and Passive Hyperventilation on Cerebral Blood Flow, Cerebral Oxygen Consumption, Cardiac Output and Blood Pressure of Normal Young Men. J. Clin. Invest. 25: 107 (1946).

31. Swensson, S. Alyar. Management of the Engström Respirator in Early Infancy. Arch. Dis. Childhood. 37: 156 (1962).

32. Gondon, E. D. Carbon Monoxide Encephalopathy. Brit. M. J. 5444: 1232 (1965).

33. Maciver, IAN W. \& Matheson, John G. The Role of Respiratory Insufficiency in Mortality or Severe Head Injuries. Lancet. $i$ : 390 (1958).

34. Guess, W. L. \& Autian, J. Biological Testing of Plastics to be Used in Medical Practice. Am. J. Hosp. Pharm. 21: 260 (1964).

35. Guess, W. L. \& Autian, J. A Note on the Response of an Extract from a Medically Used Polyvinyl Chloride Tubing. Acta Pharm. Suec. 2: 273 (1965). 